\title{
Environmental and management issues associated with backpacker tourism in mountainous protected areas, China
}

\author{
Jing Wu, Jinyu Shen, Yilei Hou \& Yali Wen
}

Keywords: backpacker tourism, environmental impact, nature reserve management, mountainous protected areas, China

\section{Abstract}

Backpacking is an increasingly popular, but sometimes controversial, activity in protected areas. Very few studies have examined the impacts associated with backpacker tourism in environmentally sensitive regions of China. Using data collected from a survey of backpackers visiting Mt Taibai in the Qinling Mountains, this paper analyses the environmental and management challenges posed by travellers in a protected area. We observed that many backpackers gained unauthorized access to the study area, sometimes even to the most fragile sections of natural reserves. This unauthorized use of protected areas poses serious risk of injury and has environmental implications, including damage to vegetation and soils, pollution and wildlife habitat disturbance. But most respondents had little awareness of their environmental impacts and held negative attitudes toward restricted activities in the non-tourist district of protected areas. To promote environmentally responsible attitudes, reduce the risk of accidents and alleviate pressure on reserve managers, we recommend strengthening regulations as well as developing a multi-department management system, expanding community participation and improving environmental education. In a way, this study provides a strategic plan for improved accessibility and land management practices in mountainous protected areas.
Profile

Protected area

Mount Taibai National

Nature Reserve

Mountain range

Qinling Mountains

Country

P. R. China

\section{Introduction}

Backpacking has become an increasingly popular form of recreation in recent decades. Indeed, the presence of backpackers has become so palpable it can hardly be denied (Spreitzhofer 1998; Hampton 1998), although many countries still do not keep specific statistics on backpacker tourism (O’Reilly 2006). Backpacking is treated as part of the wider mainstream tourism industry in the $21^{\text {st }}$ century, given that many tourists are searching for forms of travel that provide alternative experiences (Ooi \& Laing 2010). Meanwhile, economic and political developments associated with globalization have made this form of travel more accessible and practical than ever before (O'Reilly 2006).

There is growing academic interest in analysing the backpacker tourism phenomenon, which started in earnest in the late 1960s. Researchers have used different concepts to describe backpacking but still lack a consensus on its actual meaning (Ooi \& Laing 2010). In general, backpackers are viewed as pursuing a deep experience with local lifestyles (MaOz 2007). That is, they are more concerned with authenticity (Noy 2004) and tend to travel more widely than other tourists, seeking unusual or out-of-the-way locations and / or experiences (Haigh 1995). Recently, however, short-term backpacking has emerged. Such tourists travel in a backpacker-like manner, behave as ordinary backpackers, but within the time limits of cyclical holiday patterns, and cover less ground during a trip (Sørensen 2003).
Backpacker tourism in China

The emergence of backpacker tourism in China is relatively recent, making research of the phenomenon especially urgent and useful. Chinese backpackers are known colloquially as Donkey Friends, - Donkey is a homophone for travel in Chinese - which reflects backpackers' obsession with tourism (Lim 2009; Wang 2012). Moreover, the donkey, commonly illustrated as bearing great weight and doing hard work, is a vivid metaphor for the backpacker travel spirit.

In China there is increasing demand among backpackers for new experiences and destinations, resulting in unauthorized use of protected areas. This unauthorized use has contributed to criticism and examination of potential negative impacts (Fan et al. 2013; Zhao \& Dang 2011). Protected areas form the cornerstone of most global conservation strategies (Wu et al. 2011), and the primary legal mandate in China is to safeguard endangered species and ecological integrity. Tourism activities in protected areas are usually restricted to areas where environmental impact can be minimized, and the use of protected areas is often zoned. Backpacking is permitted in most forest parks and tourism districts, but areas designated as remote wilderness, where there is limited access, generally hold more appeal for Chinese backpackers (Zhao \& Dang 2011). Thus, unauthorized access to protected areas has become an important environmental and land reserve management issue, particularly within natural reserves.

Limited research is available on unauthorized backpacking in protected area, but there are some studies 


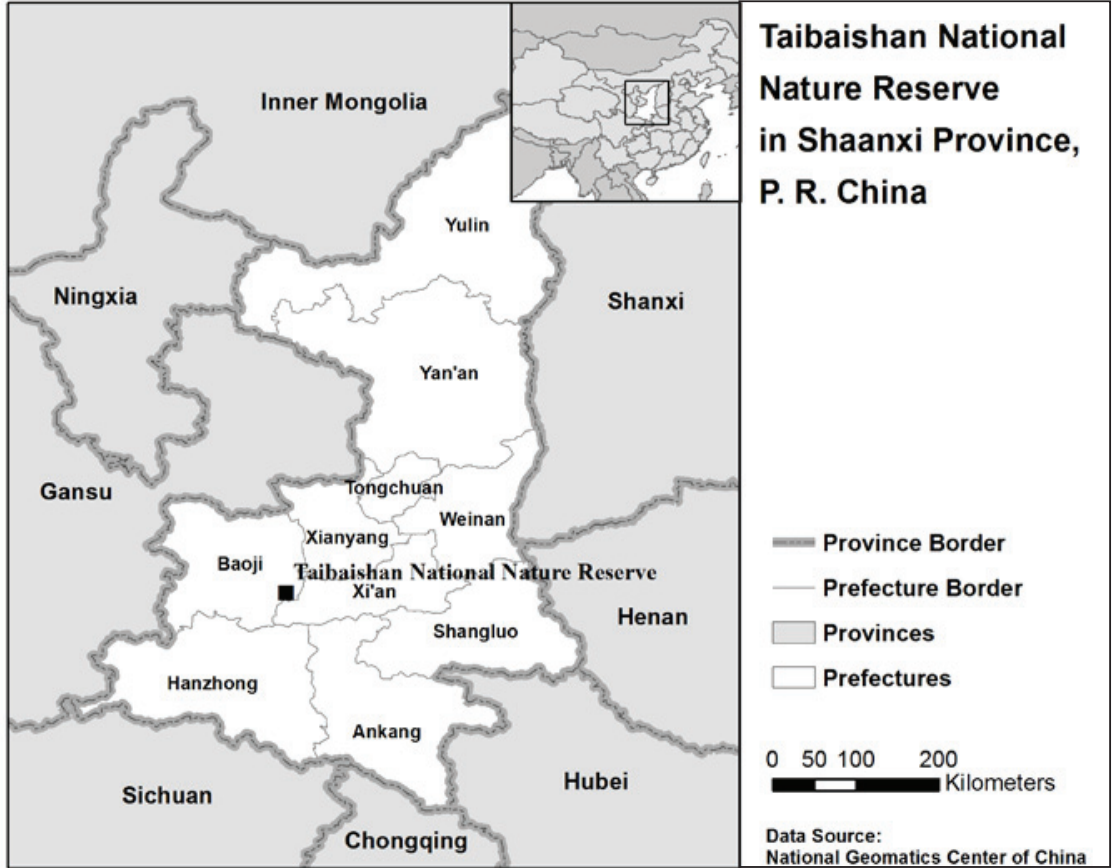

Figure 1 - Map showing the location of Taibaishan National Nature Reserve in the Qinling Mountains, Shaanxi Province, China.

of recreational use in protected areas and associated activities, such as hiking, mountain biking, and horseback riding (Pickering et al. 2010; Barros et al. 2013; White et al. 2006; Pickering et al. 2013). Horseback riding and mountain biking are often perceived as high-impact activities, particularly in natural reserves, because of their potential to degrade trails, natural vegetation and soils and disturb wildlife (Newsome et al. 2008; White et al. 2006). It is important to note that these environmental impacts are similar in type, but may differ in intensity (Pickering et al. 2010; Newsome \& Davies 2009).

\section{Research aims}

This paper analyses the environmental and management issues associated with one category of backpackers travelling in a protected area, using data collected from a survey of backpackers travelling near Mt Taibai in the Qinling Mountains, China. Tourists directly affect the natural environment through their behaviour, although individual perception of impact varies considerably. Therefore it is crucial to seek a better understanding of how backpackers see their environmental impacts, especially in mountainous wilderness areas. Our aim in this paper is to determine the main routes across the mountains, how backpackers perceive their environmental impacts and the management challenges posed to protected areas. Ultimately the goal is to provide a strategic plan for improved accessibility and land management practices in China's natural reserves.

It is important to explain the definition of backpacker used in this study. The highest mountain in north-western China is Mt Taibai (3771.2 $\mathrm{m}$ a.s.l.) in the Qinling Mountains. This peak and the surrounding protected area is a popular destination for backpackers
(Fan et al. 2013; Zhao \& Dang 2011). Visitors to the area travel in small groups, carry all of their belongings on their back, search for authentic or unusual experiences (Zhao \& Dang 2011). For most backpackers, apart from layover days in adjacent communities, it only takes five to seven days to hike across the main area of the Qinling Mountains. This paper therefore focuses on short-term backpackers and relies on selfidentification of backpacker status, thus acknowledging the diverse and varied nature of what it means to be a backpacker (Ooi \& Laing 2010).

\section{Study area}

The Qinling Mountains are located in north-western China. The unique geographical location makes these mountains a vital distribution zone for the giant panda, golden monkey, takin, crested ibis and other endangered wild animals. Mt Taibai is the highest mountain in the Qinling Mountains, covering an area of approximately $2379 \mathrm{~km}^{2}$ (Figure 1). Since 1988, three nature reserves, including one national nature reserve and four national forest parks, have been established near Mt Taibai.

Mt Taibai has become a desirable destination for backpackers because of its high altitude, primitive natural environment and abundant biological assets. The main backpacker hiking routes are outlined in Figure 2 using monitoring data provided by the Taibai Mountain National Nature Reserve (NR) as well as data obtained through questionnaire surveys. Each route's name, altitude and location in the nature reserve is explained in Table 1. 


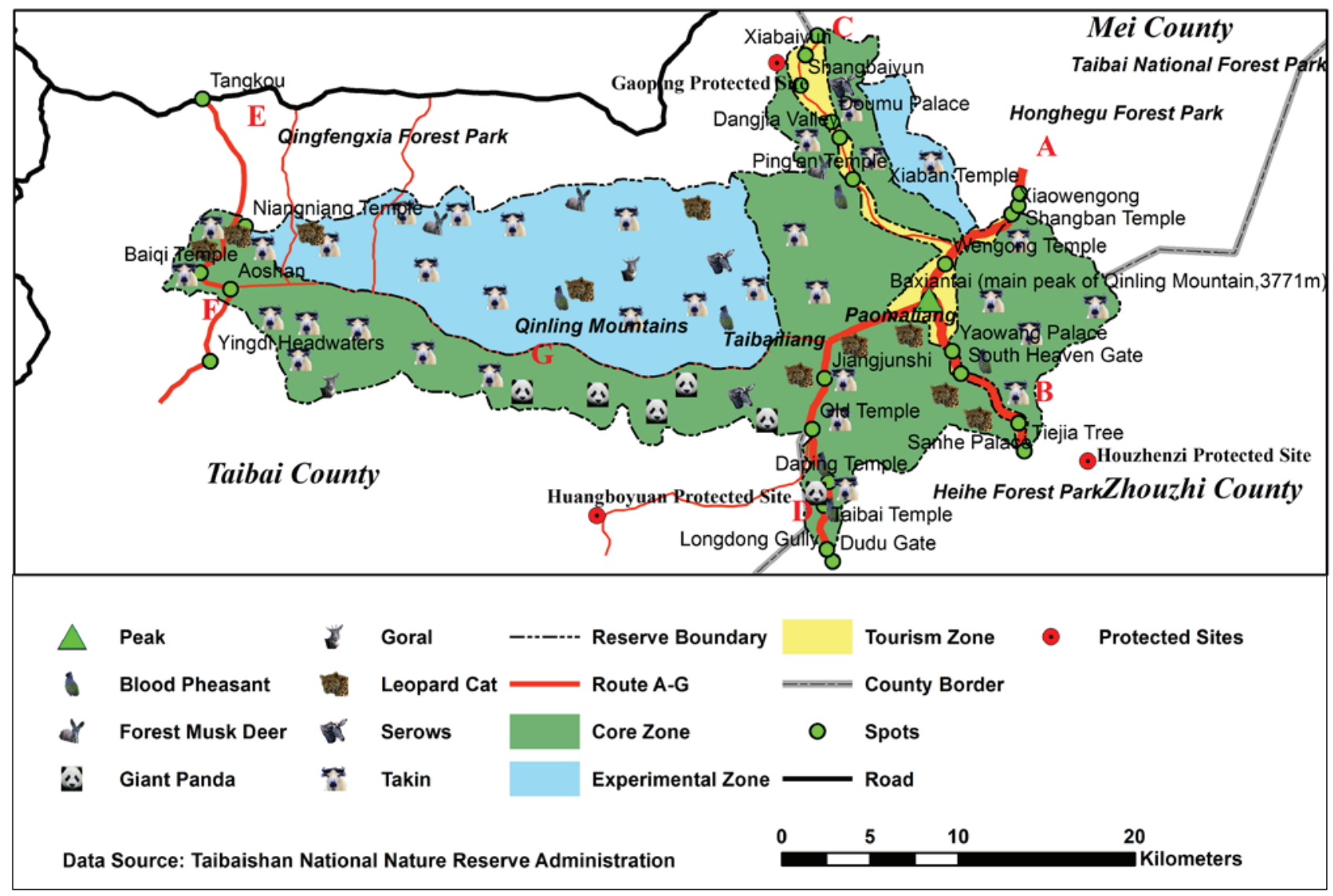

Figure 2 - Map showing the main backpacking routes near Mt Taibai in the Qinling Mountains, China. Note: The coloured areas delineate Taibai Mountain National NR. The reserve has three different levels of protection: no access is permitted in the core zone; scientific research and environmental education are allowed in the experimental zone; civilian activities (e.g. breeding endangered species, recreation) are permitted only in the tourism zone.

\section{Materials and Methods}

\section{Data collection}

Data were obtained through questionnaire surveys administered to backpackers travelling near Mt Taibai from September 2012 to October 2013. This region was selected for its high ecological value and popularity among backpackers. In order to ensure the sample adequately represented the population in the study area, a pilot study measuring the validity and userfriendliness of the questionnaire was carried out in June 2012. Interviewees were chosen at random, but participants had to adhere to the characteristics of a short-term backpacker as defined by this study. To facilitate sampling, study locations were selected according to season, hiking route and tourist attractions. A total of 239 interviews were conducted and 222 valid questionnaires were collected. All respondents self-identified as backpackers and were further verified through direct questioning by the researchers. In addition, 30 semi-structured interviews with managers of national nature reserves and forest parks were conducted, recorded and transcribed to provide a broader perspective of backpacker tourism.

Most interviews were conducted face-to-face and a few by email. Interviews were conducted in three phases. First, 151 questionnaires were collected by graduate students near the exit of the main hiking route. Second, 42 interviews were conducted on the road by staff in various sections of protected areas. The remaining interviews (46) were conducted through a network with the help of outdoor club organizers. Eligible backpackers who agreed to take part were contacted by email after being informed about the aims and outline of the study.

\section{Data analysis}

Data were analysed both qualitatively and quantitatively. Data from the semi-structured interviews with managers were transcribed for analysis and some direct quotations from respondents are used in this study to illustrate reasoning and purposes. The majority of the quantitative data from the closed-ended questions posed to the backpackers were analysed using descriptive statistics (percentage). Perceptions of respondents were then rated using a five-point Likert scale from very little (1) to very much (5) to allow for statistical analysis. 
Table 1 - Number of backpackers and explanation of each backpacking route in Mt Taibai in the Qinling Mountains.

\begin{tabular}{|c|c|c|c|}
\hline Route & Name and altitude of the route & Location in protected area & Respondents \\
\hline A & $\begin{array}{l}\text { Xiaban Temple }(2830 \mathrm{~m}) \text { - Shangban Temple }(3210 \mathrm{~m}) \text { - Wengong Temple } \\
(3480 \mathrm{~m}) \text { - Baxiantai }(3771.2 \mathrm{~m})\end{array}$ & $\begin{array}{l}\text { Mostly in tourism zone, a } \\
\text { small part in core zone }\end{array}$ & $70(31.53 \%)$ \\
\hline B & $\begin{array}{l}\text { Tiejia tree }(1400 \mathrm{~m}) \text { - Sanhe palace-South heaven gate }(3120 \mathrm{~m}) \text { - Yaowang } \\
\text { palace-Baxiantai }(3771.2 \mathrm{~m})\end{array}$ & $\begin{array}{l}\text { Mostly in tourism zone, a } \\
\text { small part in core zone }\end{array}$ & $65(29.28 \%)$ \\
\hline c & $\begin{array}{l}\text { Xiabaiyun (1 } 555 \mathrm{~m}) \text { - Shangbaiyun (1 } 779 \mathrm{~m}) \text { - Ping'an temple (2 } 782 \mathrm{~m}) \text { - Baxiantai } \\
(3771.2 \mathrm{~m})\end{array}$ & In tourism zone & $11(4.95 \%)$ \\
\hline $\mathrm{D}$ & $\begin{array}{l}\text { Dudu gate }(1778 \mathrm{~m}) \text { - Old temple (3059 m) - Jiangiunshi (3300 m) - Paomaliang } \\
(3485 \mathrm{~m}) \text { - Baxiantai }(3771.2 \mathrm{~m})\end{array}$ & Totally in core zone & $78(35.14 \%)$ \\
\hline $\mathrm{E}$ & Taibai county - Yingdi headwater (2245 m) - Aoshan (3452 m) & Mostly in core zone & $39(17.57 \%)$ \\
\hline $\mathrm{F}$ & $\begin{array}{l}\text { Tangkou (1862 m) - Niangniang temple }(2918 \mathrm{~m}) \text { - Baiqi temple (3343 m) - } \\
\text { Aoshan (3452 m) }\end{array}$ & A small part in core zone & $31(13.96 \%)$ \\
\hline G & $\begin{array}{l}\text { Aoshan (3452 m) - Taibai temple (3360 m) - Taibailiang (3360 m) - Paomaliang } \\
\text { (3485 m) - Baxiantai (3771.2 m) }\end{array}$ & Mostly in core zone & $21(9.46 \%)$ \\
\hline
\end{tabular}

\section{Results}

\section{Backpacking routes}

Seven main backpacking routes were analysed in this study (Figure 2). To facilitate analysis these routes have been simplified into alphabetic characters (Route A to Route G). Adventurous or experienced backpackers have the option of combining any of the routes with other hiking trails to cross $\mathrm{Mt}$ Taibai. The number of backpackers who took each route is shown in Table 1 . All of the routes converge on the main peak, Baxiantai, in the Qinling Mountains, which serves as an indicator that one is an experienced donkey friend.

\section{Environmental perceptions and impacts}

With the exception of Route C, backpacking routes in Mt Taibai either partly or totally cross the core zone of a protected area that civilians are strictly prohibited from entering. We may attribute this to the fact that for many backpackers there is an allure to pursuing what they consider authentic, unusual or exciting experiences. The core zone of protected areas with abundant rare species and difficult terrain holds a high degree of mystique and challenge for backpackers. The majority of respondents admitted that they knew their destination was located in a protected area. However, with regard to whether they were aware of the boundary of a protected area, a high percentage of respondents answered, "I don't know." A similar outcome was obtained for the questions, "Do you know the functional zoning of a protected area?" and "Do you know the key protected objects in this protected area?" The low degree of awareness among backpackers in the area reflects poorly on land management practices as well as on environmental education efforts. Details are presented in Table 2.

The majority of respondents stated that they had removed litter from a protected area. However, the amount of litter and visible fire damage recorded by staff in protected sites reflected the opposite of respondents' answers. Results show that the litter left behind by backpackers greatly increases pressure on waste disposal and conservation efforts in nature reserves (Table 3). In general respondents preferred camping in the wild to get overnight accommodations for free. When asked if they had seen rare wild animals when backpacking in protected areas, $30.18 \%$ of respondents answered "yes," which gives indirect evi-

Table 2 - Respondents' understanding of protected area, waste disposal, and the probability of encountering wild animals.

\begin{tabular}{|c|c|c|c|}
\hline Questions & Alternative answers & $\mathbf{N}$ & $\%$ \\
\hline \multirow[t]{2}{*}{ Did you know the backpacking destination was in a protected area? } & Yes & 191 & 86.04 \\
\hline & No & 31 & 13.96 \\
\hline \multirow[t]{2}{*}{ Do you know the boundary of Mt Taibai NR? } & Yes & 34 & 15.32 \\
\hline & No & 188 & 84.68 \\
\hline \multirow[t]{2}{*}{ Do you know the function zoning in Mt Taibai NR? } & Yes & 13 & 5.86 \\
\hline & No & 209 & 94.14 \\
\hline \multirow[t]{2}{*}{ Do you know the key protected objects in Mt Taibai NR? } & Yes & 40 & 18.02 \\
\hline & No & 182 & 81.98 \\
\hline \multirow[t]{4}{*}{ How do you deal with litter when backpacking in Mt Taibai NR? } & Litter in the protected area & 4 & 1.8 \\
\hline & Take away from protected area & 186 & 83.78 \\
\hline & Buried on the spot & 19 & 8.56 \\
\hline & Burn away & 13 & 5.86 \\
\hline \multirow[t]{2}{*}{ Have you seen rare wild animals when backpacking in the protected area? } & Yes & 67 & 30.18 \\
\hline & No & 155 & 69.82 \\
\hline \multirow[t]{2}{*}{ Will you be camping in the protected area? } & Yes & 142 & 63.9 \\
\hline & No & 80 & 36.03 \\
\hline
\end{tabular}

Note: data were collected from staff monitoring the Huang Baiyuan protected site during October 2013. 
Table 3 - The amount of litter and evidence of fire on the way to the Old Temple from Dudu Gate.

\begin{tabular}{|l|l|r|r|r|r|r|}
\hline \multirow{2}{*}{ Items } & Location & $\begin{array}{l}\text { Dudu Gate - } \\
\text { Taibai Temple }\end{array}$ & $\begin{array}{l}\text { Taibai Temple - } \\
\text { Da Ping }\end{array}$ & $\begin{array}{l}\text { Da Ping - } \\
\text { Linggong Tai }\end{array}$ & $\begin{array}{l}\text { linggong Tai - } \\
\text { Old Temple }\end{array}$ & Total \\
\hline \multirow{2}{*}{ Litter } & Pollution area $\left(\mathrm{m}^{2}\right)$ & 342.85 & 411.84 & 692.4 & 1308.37 & 2755.46 \\
\cline { 2 - 7 } & Number of littering places & 26 & 71 & 61 & 67 & 255 \\
\hline \multirow{2}{*}{$\begin{array}{l}\text { Traces } \\
\text { of fire }\end{array}$} & Area $\left(\mathrm{m}^{2}\right)$ & 1.58 & 5.93 & 1.57 & 36.86 & 45.94 \\
\cline { 2 - 7 } & Number of traces & 2 & 3 & 2 & 14 & 21 \\
\hline
\end{tabular}

dence of the negative impact of backpackers on wildlife habitats.

Given the participants in this study had unauthorized access to protected areas, we attempt to determine how backpackers perceived the negative impacts associated with their activities. The mean and standard deviation score of each answer are shown in Table 4, indicating that respondents have little awareness of their environmental impacts.

The general attitude of backpackers towards tourism in protected areas was also considered (Table 5). When asked whether "wildlife and ecotopes are affected once you access a protected area," half of the respondents believed ecotopes would not be affected if they tried to avoid disturbing animals, destroying vegetation or leaving litter in a protected area. In addition, more than half of respondents disagreed with the idea of restricting backpackers' activities to tourist districts in protected areas. They held the views that 1) backpackers generally consume fewer resources and do not produce pollution, and therefore are kinder to the environment, and 2) protected areas with extraordinary natural scenery and steep mountains are the best place for backpackers who seek adventures or out-of-theway experiences.

\section{Discussion}

\section{Environmental impact associated with} backpacking in mountainous protected areas

Mountainous protected areas are a strong attraction for Chinese backpackers, who are looking for excitement and adventure, which in turn poses challenges for conservation. Our study shows that most backpacking routes in the mountain area fall within pro- tected areas; moreover, quite a few of these routes run across a substantial part of the core zone of protected areas. Unauthorized backpacking in protected areas presents serious safety concerns and has environmental implications because of limited road access and the high conservation value of this region. Although backpackers often follow well-trodden paths, new hiking routes near or in protected areas are continuously being explored as backpacker tourism increases. For many backpackers, the less travelled, more difficult, routes hold a high degree of mystique and confer greater status with peers (Riley 1988).

With the rise in the number of backpackers in protected areas goes an inevitable increase in negative environmental impacts. Activities in protected areas have been found in a wide range of ecosystems (Marion \& Leung 2011; Kerbiriou et al. 2009). Although the participants in this study stated that their way of backpacking is environmentally friendly and does not cause pollution, behaviours such as pitching tents, littering, making noise and creating informal trails all increase impacts on protected areas and contribute to degraded ecosystems. Researchers have demonstrated that hiking in protected areas causes ecological pressure that leads to direct and indirect environmental impacts, which may irreversibly damage fragile mountain ecosystems (Pickering et al. 2011; Barros et al. 2013). Studies of mountain hiking sites have found impacts on vegetation and soils, including a decrease in vegetation height and cover, soil compaction and loss, reduced soil moisture and changes in vegetation composition (Leung \& Marion 2000; Randall \& Newsome 2009). Moreover, the capacity of mountain ecosystems to recover from human disturbance is limited and damage to vegetation and soils often lasts for decades due

Table 4 - Mean and standard deviation scores associated with perceptions of environmental impacts of backpacking in protected areas.

\begin{tabular}{|l|c|c|}
\hline Respondents' perception of environmental impact on protected area & Mean & SD \\
\hline Environmental pollution & 1.948 & 1.037 \\
\hline Soil compaction and loss & 1.774 & 1.035 \\
\hline Natural vegetation deterioration & 2.017 & 1.076 \\
\hline Wildlife disturbance & 2.586 & 1.195 \\
\hline Adverse visual impact of landscape & 1.698 & 0.953 \\
\hline Wildlife habitat destruction and fragmentation & 2.897 & 1.360 \\
\hline Geologic landforms destruction & 1.810 & 0.995 \\
\hline Damage to the original ecological landscape & 1.897 & 1.066 \\
\hline
\end{tabular}

Note: $1=$ very little, $2=$ little, $3=$ neutral, $4=$ much and $5=$ very much; environmental pollution includes litter pollution, water pollution, noise pollution, air pollution, etc. 
Table 5-General attitudes toward backpacker tourism in protected areas.

\begin{tabular}{|l|l|r|r|}
\hline Questions & Alternative answers & \multicolumn{1}{c|}{ N } & \multicolumn{1}{c|}{$\%$} \\
\hline Wildlife and ecotope would be affected once you access the protected area. & Agree & 98 & 44.14 \\
\cline { 2 - 4 } & Disagree & 124 & 55.86 \\
\hline $\begin{array}{l}\text { What's your attitude towards the stipulation that backpackers are prohibited in non-tourist districts in } \\
\text { a protected area? }\end{array}$ & Agree & 96 & 43.24 \\
\cline { 2 - 4 } & Disagree & 126 & 56.75 \\
\hline
\end{tabular}

to slow plant growth, sloping terrain, and thin soils (Körner \& Ohsawa 2005).

The impact of unauthorized backpacking is not limited to vegetation changes and soil loss; visitor activities in non-tourism districts may also have a range of effects on rare wild animals (Behrens et al. 2009). Our study shows that backpackers' interests were not limited to natural scenery, but also focused on species and natural ecology. Moreover, most backpacking areas are important habitats for the giant panda ( $A$ iluiopodidae melanoleuca), takin (Budorcas taxicolor), forest musk deer (Moschus berezovskii), leopard cat (Prionailurus bengalensis) and other species (Figure 2), so backpacker activities in these areas have a direct impact on habitat and wildlife behaviours. This study does not provide an assessment of the impacts of backpacker tourism on wildlife, but a high percentage of respondents in this study saw rare wild animals in protected areas. The resulting impacts, small though they may be individually, may become serious because of the location in which they occur or because of their cumulative effects (Butler 1999).

Backpacker behaviours directly affect the intensity of their impacts (Cole 2004). Studies have demonstrated that damage may be mitigated through careful consideration of campsite location, hiking route and waste disposal (Hercock 1999; Growcock 2005). However, this study found that reserve managers strongly disagreed with respondents' statements that they are environmental friendly and leave no litter. Rather they reported that camping areas used by backpackers had more litter and more traces of fire and tree damage. These findings indicate that most backpackers are conscious of environmental protection, but have a limited capacity to adopt environmentally responsible behaviour. Moreover, because backpackers have minimal understanding of protected areas in terms of boundaries, zoning and protection, it is important to improve their overall ecological worldview through education (Liu et al. 2010).

Backpacker attitudes towards environmental impacts in protected areas go some way toward determining whether they embrace environmentally responsible behaviour. Promoting environmentally responsible behaviour has become one of the major objectives of management strategies to minimize visitors' inappropriate behaviours (Kim 2012). From this perspective, the low perception of environmental impacts evident in this study may pose negative implications. For example, if an individual does not believe backpacking in protected areas is harmful, they may continue their behaviours over the course of several years, which in turn adversely affects the environment and may also negatively influence companions. Considering the relationship between environmental behaviour and attitudes, backpackers may either jeopardize the environment or encourage harmful behaviour without realizing it. In addition, negative attitudes toward restricting backpacker activities may inhibit selfregulation and make it hard to achieve conservation goals for threatened species in rich biodiversity areas. The non-tourist districts of mountainous protected areas have a primeval landscape, rich biodiversity and well-preserved quaternary glacial relics, which tend to attract adventurous backpackers. Most respondents in this study gained unauthorized access to the core zone of protected areas and had low awareness of their potentially negative impacts. They stated that individuals have the right to enjoy the beautiful landscape of the non-tourist district in protected areas as long as they minimize their impact, so backpacking is undoubtedly the best travel choice. In some respects these attitudes put great pressure on land management and natural conservation for protected areas.

\section{Nature reserve management challenges and implications}

Mitigating backpacker impacts is a challenge with no easy resolution for reserve managers. Backpackers hiking in non-tourism districts could result in a range of environmental impacts for protected areas, particularly those in the core area of reserves. Nevertheless, it is difficult for reserve management agencies to adopt concrete actions to restrict entry because of a lack of laws and rules to implement regulations. In reality an oral warning is the most common punishment in Chinese protected areas, but this method seems an inefficient deterrent to backpackers. A policing strategy might reduce the likelihood of unauthorized backpacking in protected areas, but how successful such an approach would be is not clear owing to the high mountains and thick forests, limited road access, large managing scope and limited staff in protected areas. Moreover, there is currently minimal public funding for nature reserve agencies, which limits their ability to mitigate environmental impacts, carry out night patrols or guarantee backpacker travel safety.

Despite these challenges, there are several options open to reserve managers when dealing with unauthorized backpackers and their associated impacts. First, accelerating the legislative process, along with establishing and improving multi-department man- 
agement, should be seriously considered. There is a need to strengthen environmental policies associated with tourism in protected areas and to enforce laws and regulations designed to punish people who enter nature reserves without approval. In order to better control backpacking activities and reduce negative impacts, the three nature reserves, four forest parks and seven forest farms in the Mt Taibai region should collaborate under a unified leadership.

A second option is establishing a community participation mechanism near protected areas (Liu et al. 2010). Residents in adjacent communities are especially encouraged to be involved in participatory programmes designed to curb environmentally harmful behaviours, especially regarding unauthorized backpacking in natural reserves. Patrol forces can be beefed up with local residents near the main unauthorized backpacking routes. A third option is to develop education programmes that raise environmental awareness among backpackers. Education initiatives could focus on the potential negative impacts associated with backpacking in nature reserves, the responsibilities of an environmentally friendly backpacker, safety matters and knowledge of protected areas. This strategy has been demonstrated to be useful for environmental education in tourism areas (Ming et al. 2000).

\section{Acknowledgments}

Grants from the programmes Key Techniques of Effective Monitoring, Evaluation and Early Warning in Nature Reserves of the Ministry of Science and Technology State Special Fund for Public Interest (201404422) funded this research. Thanks go to Mengjie Liu, Yanmei Ren, Yang Gao and Zhao Zheng for their assistance in data collection from the questionnaires. Special thanks to Chongde Hu for supplying us with data on the study area and for assistance with information collection. Finally, appreciation is due to the anonymous reviewers of eco.mont.

\section{References}

Barros, A., J. Gonnet \& C. Pickering 2013. Impacts of informal trails on vegetation and soils in the highest protected area in the Southern Hemisphere. Journal of environmental management 127: 50-60.

Behrens, D.A., B. Bednar-Friedl \& M. Getzner 2009. Sustainable management of an alpine national park: handling the two-edged effect of tourism. Central European Journal of Operations Research 17(3): 233-253.

Butler, R.W. 1999. Sustainable tourism: A state-ofthe-art review. Tourism geographies 1(1): 7-25.

Cole, D.N. 2004. Impacts of hiking and camping on soils and vegetation: a review. In: Buckley, R. (ed.), Environmental Impacts of Ecotourism: 41-60. New York.

Fan, S.W., Y. Yan \& S.J. Zhang 2013. The Backpacker's Perceived Risk in Qinling Mountain. Henan Science 8(31): 1322-1327 [in Chinese].
Growcock, A. 2005. Impacts of camping and trampling on Australian alpine and subalpine vegetation and soils. $\mathrm{PhD}$ Thesis, School of Environmental and Applies Sciences, Griffith University, Gold Coast.

Haigh, R. 1995. Backpackers in Australia. Occasional Paper No. 20, Canberra: Bureau of Tourism Research.

Hampton, M.P. 1998. Backpacker tourism and economic development. Annals of Tourism Research 25(3): 639-660.

Hercock, M. 1999. The impacts of recreation and tourism in the remote North Kimberly region of Western Auatralia. The Environmentalist 19: 259-275.

Kerbiriou, C., L. Isabelle, R. Alexandre, P. Emmanuelle, G. Françoise \& R. Julliard 2009. Tourism in protected areas can threaten wild populations: from individual response to population viability of the chough Pyrrhocorax pyrrhocorax. Journal of Applied Ecology 46: 657-665.

Kim, A.K. 2012. Determinants of tourist behaviour in coastal environmental protection. Tourism Geographies 14(1): 26-49.

Körner, C. \& M. Ohsawa 2005. Mountain systems. In: Hassan, R., R. Scholes \& N. Ash (eds.), Ecosystems and Human Well-being: Current State and Trends 1: 681716. Washington.

Leung, Y.F. \& J.L. Marion 2000. Recreation impacts and management in wilderness: A state-of-knowledge review. In: Cole, D.N., S.F. McCool, W.T. Borrie \& J. O'Loughlin (comps.), Wilderness science in a time of change conference Volume 5: Wilderness ecosystems, threats, and management; 1999 May 23-27; Missoula, MT. Proceedings RMRS-P-15-VOL-5: 23-48.

Lim, F.K.G. 2009. 'Donkey Friends' in China: The Internet, Civil Society, and the Emergence of the Chinese Backpacking Community. In: Winter, T., P. Teo \& T.C. Chang, Asia on Tour. 291-301.

Liu, J., Z. Ouyang \& H. Miao 2010. Environmental attitudes of stakeholders and their perceptions regarding protected area-community conflicts: A case study in China. Journal of Environmental Management 91: 2254-2262.

Maoz, D. 2007. Backpackers' motivations the role of culture and nationality. Annals of Tourism Research 34(1): 122-140.

Marion, J.L. \& Y.F. Leung 2011. Indicators and protocols for monitoring impacts of formal and informal trails in protected areas. Journal of Tourism and Leisure Studies 17: 215-236.

Ming, Q., H. Li \& T. Xu 2000. Research on ecotourism environment protection. Journal of Guilin Institute of Tourism 11: 55-59 [in Chinese].

Newsome, D., A. Smith \& S.A. Moore 2008. Horse riding in protected areas: a critical review and implications for research and management. Current Issues in Tourism 11(2): 144-166.

Newsome, D. \& C. Davies 2009. A case study in estimating the area of informal trail development and associated impacts caused by mountain bike activity in 
John Forrest National Park, Western Australia. Journal of ecotourism 8(3): 237-253.

Noy, C. 2004. This trip really changed me. Backpackers' narratives of self-change. Annals of Tourism Research 31: 78-102.

Ooi, N. \& J.H. Laing 2010. Backpacker tourism: sustainable and purposeful? Investigating the overlap between backpacker tourism and volunteer tourism motivations. Journal of Sustainable Tourism 18(2): 191206.

O’Reilly, C.C. 2006. From drifter to gap year tourist - mainstreaming backpacker travel. Annals of Tourism Research 33: 998-1017.

Pickering, C., J.G. Castley, W. Hill \& D. Newsome 2010. Environmental, safety and management issues of unauthorised trail technical features for mountain bicycling. Landscape and urban planning 97(1): 58-67.

Pickering, C.M., S. Rossi \& A. Barros 2011. Assessing the impacts of mountain biking and hiking on subalpine grassland in Australia using an experimental protocol. Journal of environmental management, 92(12): 3049-3057.

Riley, P.J. 1988. Road Culture of International Long-Term Budget Travelers. Annals of Tourism Research 15: 313-328.

Sørensen, A. 2003. Backpacker ethnography. Annals of Tourism Research 30(4): 847-867.

Spreitzhofer, G. 1998. Backpacking tourism in south-east Asia. Annals of Tourism Research 25(4): 979_ 983.

Wang, K. 2012. Travel behavior analysis of "Donkey Friends". Journal of Chifeng University 33(01): 110111 [in Chinese].

White, D.D., M.T. Waskey, G.P. Brodehl \& P.E. Foti 2006. A comparative study of impacts to mountain bike trails in five common ecological regions of the Southwestern US. Journal of Park and Recreation Administration 24(2): 21-41.

Wu, R., S. Zhang, D.W. Yu, P. Zhao, X. Li, L. Wang \& Y. Long 2011. Effectiveness of China's nature re- serves in representing ecological diversity. Frontiers in Ecology and the Environment 9(7): 383-389.

Zhao, Z.B. \& J. Dang 2011. The travel behavior of backpackers of mountain Taibai based on internet text content analysis. Human Geography 26(1): 134-139 [in Chinese].

\section{Authors}

Jing $W_{u}$

is a doctoral student of the School of Economics and Management at Beijing Forestry University in China. Her research interests focus on natural resource and environmental economics, ecoenvironment and tourism, sustainable development in protected areas, and ecotourism stakeholders. E-mail: wujing0520@126.com

\section{Jinyu Shen}

is a lecturer at the School of Economics and Management at South China Agricultural University in China. Her research interests include sustainable forest management, forest ecology and forestry economic theory. E-mail: sjy52852231@163.com

\section{Yilei Hou}

is a doctoral student of the School of Economics and Management at Beijing Forestry University in China. Her research interests include forest health management, community co-management and biodiversity conservation. E-mail: houyilei427@163.com

\section{Yali Wen - corresponding author}

is a professor and the vice-president of the School of Economics and Management at Beijing Forestry University in China, where he has taught since 2000. His principal research interests are forestry economics, biodiversity conservation and natural resource economics. E-mail: wenyali2003@163.com 